\title{
The Rise of Public and Private
} Digital Money: A Strategy to Continue Delivering on The IMF's Mandate 


\section{INTERNATIONAL MONETARY FUND}

\section{IMF POLICY PAPER}

THE RISE OF PUBLIC AND PRIVATE DIGITAL MONEYA STRATEGY TO CONTINUE DELIVERING ON THE IMF'S MANDATE

IMF staff regularly produces papers proposing new IMF policies, exploring options for reform, or reviewing existing IMF policies and operations. The following documents have been released and are included in this package:

- A Press Release summarizing the views of the Executive Board as expressed during its July 7, 2021 consideration of the staff report.

- The Staff Report, prepared by IMF staff and completed on June 17, 2021 for the Executive Board's consideration on July 7, 2021.

The IMF's transparency policy allows for the deletion of market-sensitive information and premature disclosure of the authorities' policy intentions in published staff reports and other documents.

Electronic copies of IMF Policy Papers are available to the public from

http://www.imf.org/external/pp/ppindex.aspx

\section{International Monetary Fund Washington, D.C.}




\section{IMF Executive Board Discusses the Rise of Public and Private Digital Money-A Strategy to Continue Delivering on the IMF's Mandate}

\section{FOR IMMEDIATE RELEASE}

Washington, DC - July 29, 2021: The Executive Board of the International Monetary Fund (IMF) discussed a staff paper on "The Rise of Public and Private Digital Money-A Strategy to Continue Delivering on the IMF's Mandate". A companion paper, "The Rise of Digital MoneyA Strategic Plan to Continue Delivering on the IMF's Mandate," was discussed by the Executive Board in an informal meeting on April 2, 2021, and is also being published today.

The paper lays out an operational strategy for the IMF to continue to deliver on its mandate given the rapidly changing developments stemming from the rise of public and private digital money.

The paper begins by summarizing the forces of change driving the adoption of digital forms of money and the new policy questions that emerge. It then offers a vision for how the IMF's core activities and output will need to evolve and discusses how the IMF intends to partner with other organizations, and to grow and structure internal resources to fulfill this vision.

The paper analyzes the wide-ranging and profound implications of digital money for the IMF membership. First, new forms of money must remain trustworthy. They must protect consumers, be safe and anchored in sound legal frameworks, and support financial integrity. Second, domestic economic and financial stability must be protected by carefully designed public-private partnerships, a smooth transition of the role of banks, and fair competition. And digital money should be designed to support climate sustainability and efficient fiscal policy. Third, the international monetary system (IMS) should remain stable and efficient. Digital money must be designed, regulated, and provided so that countries maintain control over monetary policy, financial conditions, capital account openness, and foreign exchange regimes. Payment systems must grow increasingly integrated, not fragmented, and must work for all countries to avoid a digital divide. Moreover, reserve currency configurations and backstops must evolve smoothly.

The paper provides a case of how the IMF within its mandate can help ensure that widespread ad option of digital money fosters domestic economic and financial stability, and the stability of the IMS. The paper describes how the IMF can monitor, and advise on, this rapid and complex transition for all members via its four core competencies: near universal membership; focus on macro-financial policies and spillovers; diversity of expertise; and unique ties to member countries — central banks and ministries of finance — through surveillance and capacity development. 


\section{Executive Board Assessment ${ }^{1}$}

Executive Directors welcomed the opportunity to discuss the strategy to continue delivering on the IMF's mandate given the rise of digital money. They noted that an increased adoption of digital money can foster greater efficiency and financial inclusion but also poses important challenges, and that the Fund has a critical role to play to help its members harness the benefits and manage the risks of digital money. Against this background, Directors broadly welcomed the staffs proposals for closer engagement with other organizations and country authorities involved in this area, tailored support to member countries, and broader efforts in capacity development. Noting the fast-moving developments with digitalization and the need for the Fund to act swiftly and be at the forefront in this area, and be able to assist its members, many Directors found the strategy to be appropriately ambitious. Many other Directors, however, called for further prioritization and a more phased implementation of the strategy, given the complexity of the issue and the evolving regulatory environment.

Directors agreed that digital money has implications that lie at the core of the Fund's mandate and that the Fund must be part of the discussions on these issues. In particular, digital money has wide-ranging implications for the international monetary system, spillover and crossborder effects, and the structure and stability of domestic economies. Directors, therefore, emphasized that digital money must be designed, regulated, and provided so that countries maintain control over monetary policy, financial conditions, capital account openness, and foreign exchange regimes. They also underscored that domestic economic and financial stability must be protected by carefully designed public-private partnerships, a smooth transition of the role of banks, and fair competition. Ensuring financial integration and inclusion will also be important.

Directors broadly agreed that given its mandate, near-universal membership, focus on macrofinancial policies and spillovers, diversity of expertise, and unique ties to member countries, the Fund could serve as a thought leader in analytical work and policy development, particularly on issues related to the international monetary and financial system, in close collaboration with other organizations and provide timely advice in surveillance and capacity development to its members when requested. They also saw a role for the Fund in serving as a bridge between the experience of its membership and the international policy-making process. Directors underscored the importance of tailored advice, given the different stages of development of this issue and different capacities among member countries. In particular, lowincome countries and EMDCs with less developed digital capabilities will need timely advice and capacity development assistance in macro critical areas pertinent to these countries. A number of Directors saw scope for the Fund to focus more at this stage on the development of analytical frameworks and on multilateral surveillance and capacity development, and piloting or limiting the coverage of this issue in bilateral surveillance.

Directors underscored the need to focus on the Fund's comparative advantage and to partner and collaborate with other international financial institutions, country authorities, standard setters, as well as the private sector, to maximize synergies and minimize duplication of work

\footnotetext{
${ }^{1}$ At the conclusion of the discussion, the Managing Director, as Chairman of the Board, summarizes the views of Executive Directors, and this summary is transmitted to the country's authorities. An explanation of any qualifiers used in summings up can be found here: http://www.IMF.org/external/np/sec/misc/qualifiers.htm.
} 
and foster knowledge sharing. Effective delineation of responsibilities will be important. To ensure efficiency gains and avoid putting an excessive burden on hiring external experts, Directors also emphasized the importance of internal training of fungible economists to mainstream this important workstream, as well as staff exchanges with other organizations and country authorities. They also underscored the importance of promoting knowledge sharing and cooperation between country teams and functional departments.

Directors noted the proposal on resource allocation and broadly agreed that this would need to be considered holistically in the context of the broader budget augmentation request. They called for consideration of policy options and trade-offs in deciding the resource allocations in the new areas of work. As such, Directors looked forward to the Board engagement on the proposed budget augmentation request. In their preliminary assessment, many Directors were supportive of, or open to considering, the resource request, while many other Directors suggested a more modest, phased increase in resources calibrated to actual developments and finer details on work priorities. A number of Directors emphasized the importance of prioritizing and ensuring adequate resources to assist members, particularly LICs, with low capacity for mitigating the risks from the spread of digital money and from spillovers.

Going forward, regular engagement with the Board will be important to reevaluate the appropriateness of the strategy and any agreed resource allocation. 


\section{INTERNATIONAL MONETARY FUND}

June 17,2020

\section{THE RISE OF PUBLIC AND PRIVATE DIGITAL MONEY: A STRATEGY TO CONTINUE DELIVERING ON THE IMF'S MANDATE}

\section{EXECUTIVE SUMMARY}

Rapid technological innovation is ushering in a new era of public and private digital money. Payments will become easier, faster, cheaper, and more accessible, and will cross borders swiftly. These improvements could foster efficiency and inclusion, with major benefits for all.

To reap the full benefits and manage risks, policymakers around the world are looking to step up, given the wide-ranging and profound implications of digital money.

First, new forms of money must remain trustworthy. They must protect consumers, be safe and anchored in sound legal frameworks, and support financial integrity.

Second, domestic economic and financial stability must be protected by carefully designed public-private partnerships, a smooth transition of the role of banks, and fair competition. And digital money should be designed to support climate sustainability and efficient fiscal policy.

Third, the international monetary system (IMS) should remain stable and efficient. Digital money must be designed, regulated and provided so that countries maintain control over monetary policy, financial conditions, capital account openness, and foreign exchange regimes. Payment systems must grow increasingly integrated, not fragmented, and must work for all countries to avoid a digital divide. Moreover, reserve currency configurations and backstops must evolve smoothly.

The Fund has a mandate to help ensure that widespread adoption of digital money fosters domestic economic and financial stability, and the stability of the IMS. The Fund must monitor, and advise on, this rapid and complex transition for all members as it affects its mandate. To do so, it offers four core competencies: near universal membership; focus on macrofinancial policies and spillovers; diversity of expertise; and unique ties to member countries - central banks and ministries of finance-through surveillance and capacity development.

The Fund must step up. To implement its mandate, keep pace with policy challenges, and ultimately serve its membership, the Fund must rapidly widen and deepen its work on digital money, while coordinating and collaborating closely with other institutions consistent with its mandate. The Fund must also rapidly ramp up its resources devoted to these topics. 
This paper lays out an operational strategy to do so. It begins by summarizing the forces of change driving the adoption of digital forms of money and the new policy questions that emerge (stylized in Figure 1). It then offers a vision for how the Fund's core activities and output will need to evolve. Finally, the paper discusses how the Fund intends to partner with other organization, and to grow and structure internal resources to deliver on this vision.

Figure 1. The Paper at-a-Glance

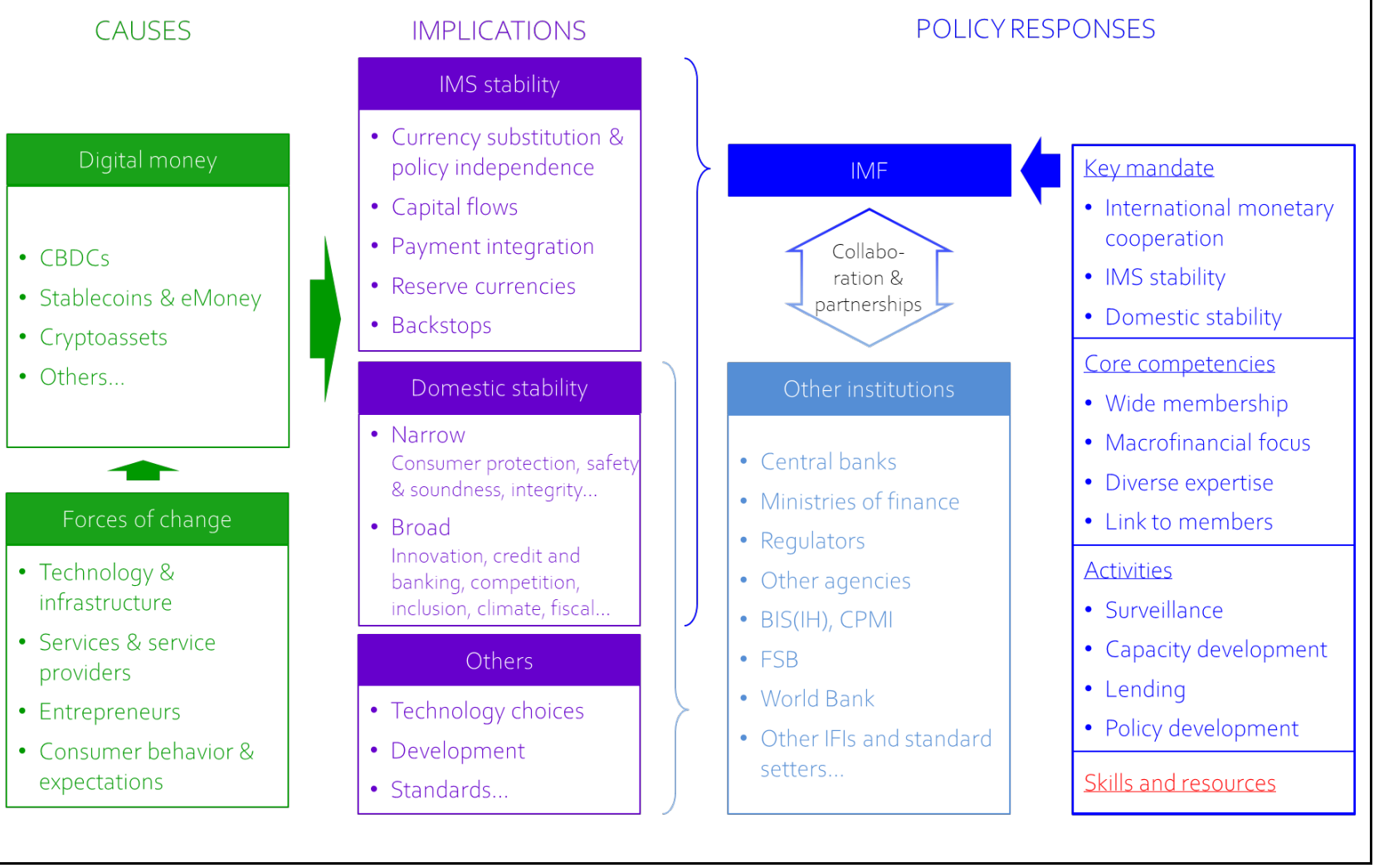


Approved By

Tobias Adrian, Camilla Andersen, Gita

Gopinath, Ceyla

Pazarbasioglu, and

Rhoda Weeks-Brown
Prepared by: Herve Tourpe (ITD); Yan Liu (LEG); Dong He, Tommaso Mancini-Griffoli (lead), and Erica Sandoval (MCM); Koshy Mathai, Piotr Nowak, and Samir Suleymanov (OMD); Giovanni Dell'Ariccia and Sole Martinez Peria (RES); Erika Tsounta (SEC); Martin Čihák and Kenneth Kang (SPR). Comments are gratefully acknowledged from departments as well as Matthew Jones and Axel Schimmelpfennig.

\section{CONTENTS}

SUMMARY OF APRIL 2021 INFORMAL BOARD PAPER

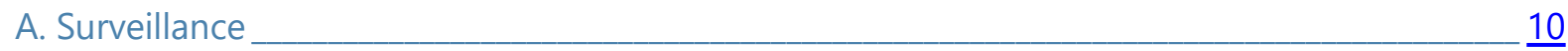

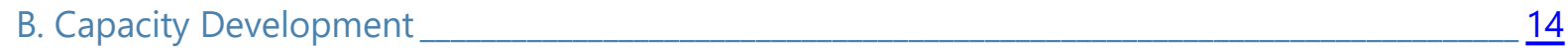

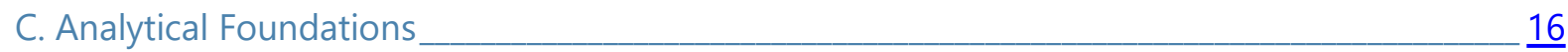

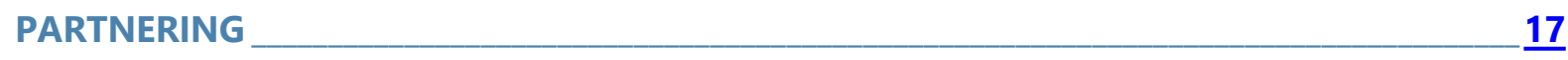

A. Guidelines for Engagement and Core Competencies _______

B. Complementarities with Other Stakeholders________

BUILDING INTERNAL CAPACITY ________

A. Necessary Skills____________

B. Internal Organization and Process __________ $\underline{20}$

C. Resource Implications___________ 21

CONCLUSION_________________________________________________________

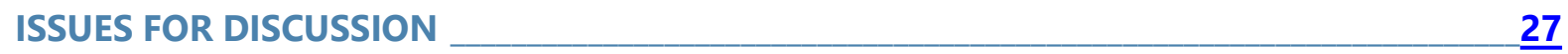

BOXES

1. Policy Questions Stemming from the Adoption of Public and Private Digital Money_____ $\underline{6}$

2. Lessons from Mainstreaming Macroprudential Policy_______ 25

\section{FIGURES}

1. The Paper at-a-Glance ________________ $\underline{2}$

2. A Basic Framework to Capture the Fund's Functions Related to Digital Money ______ $\underline{9}$

3. Illustration of the Phasing Patterns Across Major Functions______ 24

\section{TABLES}

1. Implications of Digital Money Adoption and Their Relevance for Policy Levers 
2. IMF Surveillance Would Cover the Main Areas of Policy Implications Stemming from Digital Money Adoption $\underline{10}$

3. Products and Tools for Article IV Consultations and Expected Output _____

4. Products and Tools for FSAP Missions and Expected Output____

5. Products and Tools for Multilateral Surveillance and Expected Output_______

6. Products and Tools for Capacity Development and Expected Output ______

7. Deliverables and Coverage for Analytical Foundations. _____

8. A Wide Set of Skills Is Needed to Cover All Activities and Policy Questions _____

9. Estimated Resources Split Needs by Core Activity_____ $\underline{21}$

References__________ $\underline{28}$ 


\section{SUMMARY OF APRIL 2021 INFORMAL BOARD PAPER}

1. An informal paper was presented to the IMF's Executive Board with a strategy to respond to the rapid and widespread transformation related to digital forms of money. The paper (presented on April 2, 2021, parts of which are forthcoming as IMF 2021a) provided a discussion of the new policy opportunities and challenges accompanying digital money. It then presented a case for the Fund to expand its involvement in this area, to meet its mandate, and ultimately provide value to its members.

2. This paper offers more details on how to operationalize this strategy. While it begins with a short summary of the April paper, the two papers are complementary and should be read as one.

3. Fundamental transformations are accelerating the development, deployment, and adoption of digital money. These include leaps in enabling technologies, such as distributed ledger technology (DLT), encryption, analytics of "big" datasets, and artificial intelligence. On the supply side, transformations include the entry of new firms - big techs and fintech startups -in the area of finance, as well as the emergence of new business models leveraging platforms and large established networks for distribution, and the cross-selling and tailoring of products based on users' data. On the demand side, user needs, habits, and expectations have evolved (in part due to the Covid crisis) to strongly favor digital forms of money, and policymakers are exploring how to leverage new means of payment to provide more efficient and inclusive services, while remaining relevant in the face of heightened competition from the private sector (see for instance the European Commission's "digital finance package," issued in September 2020).

4. Digital money comes in many different forms, and will continue to evolve rapidly. Publicly issued money covers central bank digital currency (CBDC). Privately issued money includes eMoney, mobile money (which is growing rapidly in East Africa), stablecoins, tokenized bank deposits, tokenized financial assets that can be seamlessly traded on liquid markets (related to the concept of iMoney in Adrian and Mancini-Griffoli (2019) and financial services emerging from Distributed Finance, or DeFi, discussed in IMF (2021a)), and even cryptoassets (which are too volatile to be technically labelled as money, though are accepted for payment). Indeed, the focus is on methods of payments, not all of which are a widespread unit of account, medium of exchange, and store of value, but all of which have potentially macro-critical implications. Clearly, this list is disparate and incomplete-publicly- and privately-issued digital money are fundamentally different, and today's list will be outdated in the near future given rapid innovation in technology and products. The term digital money is loose by design, to capture a wide set of potential forms of money. Constant change and regular discrete jumps, and the need for policy to adapt and provide guidance, are defining features of the digital age. This is especially true in the field of payments where strong network effects can lead to sudden changes in products, services, market structure, end-user habits, and related policy challenges.

5. Nevertheless, all forms of digital money have some basic features in common. Digital money offers cheap, instant, and widely accessible payments. It rewards expertise in new areas, including data analysis, programming, user-interface design, and development speed, thus opening the door to new issuers. It allows integration of money with new services and distribution platforms, some 
of which can leverage large installed bases. Its functionality evolves rapidly, in ways that are often difficult to predict. And it can be transferred much more widely, including across devices and borders.

\section{As such, public and private digital money has widespread implications, many of which} intersect with the IMF's mandate. As stated in the Articles of Agreement and in subsequent decisions of the Executive Board (such as the Integrated Surveillance Decision (2012)), the Fund has a mandate to help ensure domestic and international economic and financial stability. It is precisely in these areas that the Fund must develop policy lines relative to digital money, as well as tools, methodologies, foresight and expertise, to be able to provide effective surveillance, capacity development, analytical foundations, and lending, for the ultimate benefit of its members.

\section{In the area of economic and financial stability, rapid adoption of digital money, whether public or private, raises new policy questions, challenges, opportunities, and tradeoffs in three} areas: the IMS, broad domestic issues, and narrow domestic issues directly related to the digital form of money. These are discussed in detail in IMF (2021a) and captured succinctly in Box 1 . Three caveats are important to this list. First, the set of issues described below is a snapshot. It is likely to evolve, at times rapidly, just as digital forms of money evolve, and as adoption varies depending on technology, policy decisions, and user demand. Second, not all questions apply to all forms of digital money. Some will be more relevant to $\mathrm{CBDC}$, and others to privately-issued stablecoins, for instance. And third, not all questions will apply equally to all countries. Again, adoption will vary by country-though will likely affect a much greater share of countries through spillovers. And countries have different capacities to respond to, or leverage, digital money. Some countries, for instance, will induce greater spillovers from the introduction of $\mathrm{CBDC}$, while some countries will be more subject to currency substitution than others.

Box 1. Policy Questions Stemming from the Adoption of Public and Private Digital Money Policy questions related to the IMS include:

- Global macrofinancial integration. How can public and private digital forms of money be leveraged to foster greater integration and efficiency of international payments, and avoid fragmentation? How can we avoid a global digital divide whereby some countries struggle to keep up with technological transformations, link their payment systems to those of other countries, maintain correspondent banking relations, upgrade their regulatory and legal frameworks, and keep their payment systems safe?

- Macroeconomic policies and spillovers. How might digital money alter an economy's structure, business cycle, and exposure to currency substitutability? How could digital money affect the instruments, frameworks, conduct, and coordination of monetary, fiscal and exchange rate policies and the availability of policy space? How should "bystander" countries adjust their macro policy frameworks to protect against spillovers from digital money adoption elsewhere?

- Global imbalances and capital flows. What impact might digital money have on net and gross capital flows, market integration, the cross-border transmission of shocks, the risk of balance of payment problems, cross-currency arbitrage, and countries' choice of foreign exchange regime? How might digital money alter the effectiveness of capital account management measures (CFMs)? Or how could CBDC or other payment infrastructure be designed to minimize spillovers, and help countries retain control over domestic policies? And how could privately-issued forms of digital 
Box 1. Policy Questions Stemming from the Adoption of Public and Private Digital Money (concluded)

money be regulated to do so? How should the Fund's external sector assessments and spillover analysis account for the impact of digital money on external positions?

- Stability of the IMS. How will public digital forms of money affect the configuration of reserve currencies, and the potential transition towards new configurations be smoothed out? How might the IMS look like in 10 years, and how can digital money be leveraged or regulated to get there? How can the global financial safety net, including backstops, regional arrangements, and Fund operations be redesigned to leverage digital money?

Policy questions related to broad domestic effects include:

- Financial services, markets, and regulations. How will the role of banks evolve, and what impact might this have for the provision of credit and for financial stability? Relatedly, how should regulation evolve to ensure a level playing field and stable transition? Will DeFi impact market structure and functioning, and what role could digital money play in capital market development, functioning, structure, and efficiency? How could CBDC be designed, and privately issued money be regulated to ensure financial stability and integrity? What will be the impact on growth and productivity, as well as the balance of risks?

- Competition and innovation. What role should the public and private sectors have in the development and provision of different forms of digital money to encourage competition and innovation? How should regulation and design of different forms of digital money evolve to ensure competition and market contestability? Relatedly, what are the economics of data and to what extent can regulation of data impact market structure?

- Fiscal. How can digital money make payments between authorities and private agents more efficient, safer, and more targeted and transparent? What opportunities arise to reach the most vulnerable households, as well as reduce corruption? What are the risks to tax evasion and the opportunities to improve tax compliance? What new tax policies can be envisaged including VAT, shareholder taxation, and taxes on the value creation of data?

- Financial inclusion, and climate. How can digital money contribute to financial inclusion, and what tradeoffs might exist with access to data and privacy? How should the environmental impact (energy consumption of DLT can be extremely high) of different forms of digital money be consistently, credibly, and publicly evaluated?

Policy questions related to narrow domestic effects include:

- Consumer protection and privacy. How should privately-issued digital forms of money be designed and regulated to ensure consumer protection, and effective safety nets? What models are arising globally and which constitute best practices? How can data integrity and privacy be respected across borders?

- Legal and regulatory frameworks. How should central bank, monetary, private and other laws evolve to provide clear legal underpinning to support innovation while ensuring financial stability and integrity? How wide should the regulatory perimeter be, and how can the macro-criticality of new and rapidly evolving forms of digital money (such as cryptocurrencies) be evaluated?

- Cyber and other risks. What best practices should be implemented to ensure operational resilience of different forms of digital money, including to cyber-attacks and contagion? What new recommendations should be adopted, and how can different forms of digital money be leveraged to ensure the effective implementation of a robust anti-money laundering and combating the financing of terrorism (AML/CFT) framework, and appropriate safeguards against tax fraud? 
8. These questions require changes and innovative thinking across the policy spectrum. The questions span the mandates of central banks, ministries of finance, and other bodies. Table 1 summarizes the relevance of the new questions arising from digital money adoption to each category of policy.

Table 1. Implications of Digital Money Adoption and Their Relevance for Policy Levers

\begin{tabular}{|c|c|c|c|c|c|c|}
\hline & Structural & $\begin{array}{l}\text { Central } \\
\text { banking }\end{array}$ & Fiscal & Regulation & $\begin{array}{c}\text { Legal } \\
\text { frameworks }\end{array}$ & $\begin{array}{c}\text { Int'I } \\
\text { cooperation }\end{array}$ \\
\hline IMS & & & & & & \\
\hline Broad domestic effects & & & & & & \\
\hline Narrow domestic effects & & & & & & \\
\hline
\end{tabular}

$$
\text { Very High High Medium }
$$

Notes: Structural policies include competition policy, market and infrastructure design, partnerships with the private sector, digital identities and other measures fostering financial inclusion. Central banking policies include monetary policy, choice of FX regime, central bank access policies and operations, and CBDC design. Fiscal policies include taxation, transfers, government payments, and transparency. Regulatory policies include regulation, supervision, oversight, macroprudential policies, capital flow management measures, and data policies.

9. Many country authorities feel the need to act swiftly to tackle these rapidly evolving policy challenges and opportunities. Additional pressure comes from new private sector entrants rapidly gaining market share. Some seek guidance and regulatory clarity, while others push the regulatory perimeter and seek loopholes. The sheer pace of innovation and changes in business models require constant monitoring and updating of policies. In addition, strong network effects in payments, and high sunk costs associated with technology and coordination require swift action as first entrants impose their standards while backtracking is costly and slow. Regulation, market structure, product features, and the role of the public sector can quickly ossify around suboptimal outcomes regarding key public policy objectives such as stability, equal access, inclusion, efficiency, competition, selfdetermination, integrity, and integration.

10. To advise countries and help avoid these coordination failures, the IMF must quickly develop views on, and experience in, the policy issues related to digital money. To do so, the IMF thus plans to roll out the following operational strategy. The strategy comprises three parts: adapting and extending key functions, partnering with other stakeholders, and building internal capacity. The first part discusses what needs to be done, while the other two review how to do so.

\section{ADAPTING AND EXTENDING FUNCTIONS}

11. The Fund will continue to rely on its main functions to operationalize the digital money strategy. These are typically surveillance, capacity development, and lending. However, this paper places less emphasis on lending. As discussed in IMF (2021), lending could increase as countries run into more frequent balance of payment (BOP) problems caused by digital money adoption, if gross 
foreign capital positions grow, and capital flows become more volatile or harder to manage. However, the Fund's existing lending toolkit is available to help members address those BOP problems and will be reviewed periodically. This paper instead highlights the Fund's surveillance and capacity development functions. It also emphasizes the function of establishing a clear analytical foundation for country work. This foundation comprises two parts: first, the development of policy views and tools, such as models, methods, frameworks, data, indicators, and standards; and second, support activities by way of internal training, guidance notes, as well as review of country documents to ensure uniform and adequate treatment (although for budget purposes review is folded into the items that are reviewed). In addition, this category includes internal coordination and information sharing, as well as internal debates and brainstorming about new developments and country engagements, as recommended by the Fund's 2018 Interim Surveillance Review (IMF (2018)). Note that policy views and tools may initially be generally developed, but need to be adapted to specific countries, projects, and technologies. Especially in the rapidly evolving context of digital money, continuous and often substantial updating will be necessary in the steady state.

\section{All these stylized functions are captured in Figure $\mathbf{2}$ and used as a framework to discuss} the specific work needed to operationalize the digital money strategy. The figure further distinguishes between functions carried out mostly by area and relevant functional departments (or a mix of both). For the purposes of this paper, relevant functional departments are: FAD, ITD, ICD, LEG, MCM, RES, SPR, and STA.

Figure 2. A Basic Framework to Capture the Fund's Functions Related to Digital Money

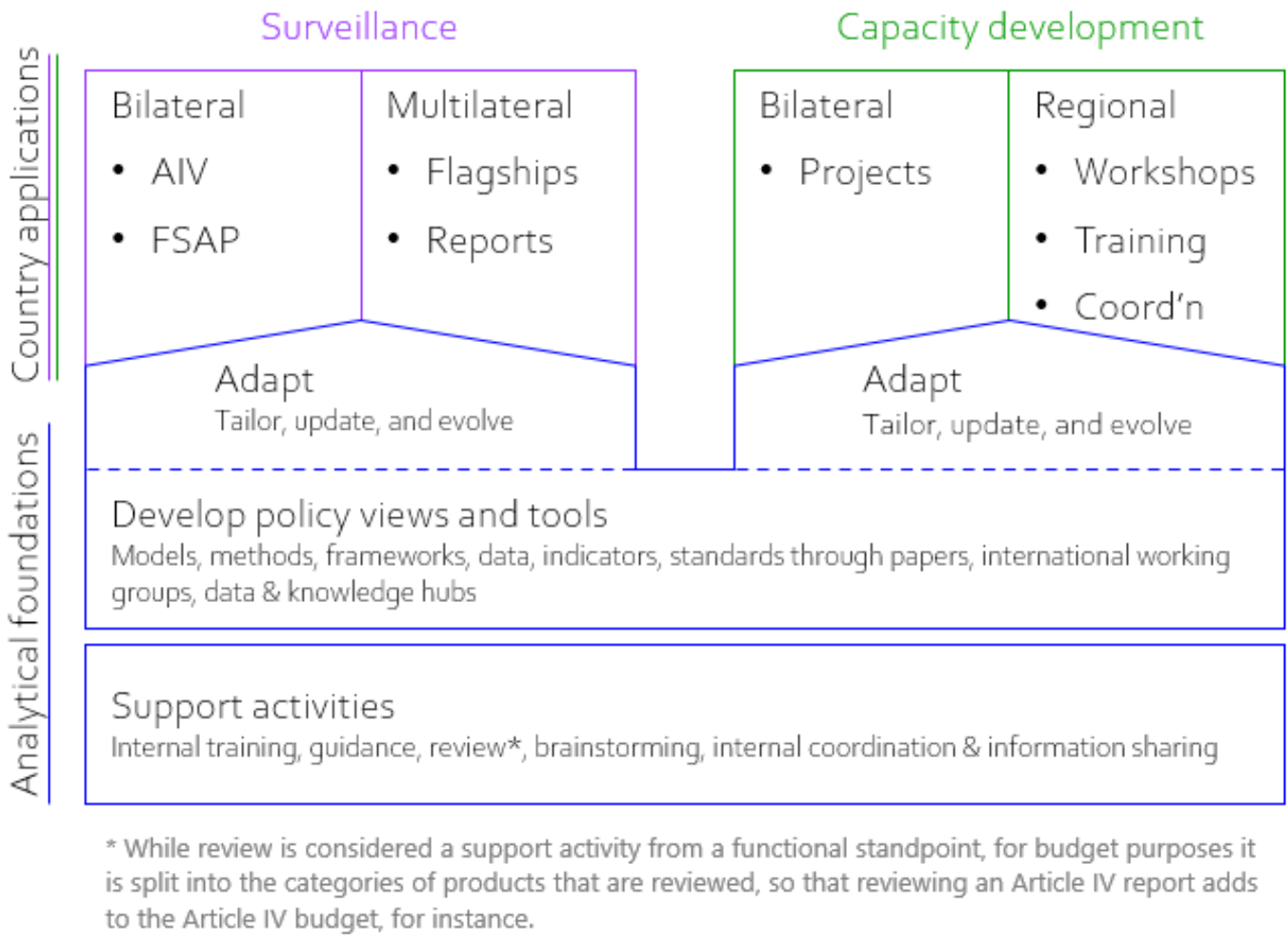

Source: Authors' illustration. 


\section{A. Surveillance}

\section{Surveillance needs to adapt to account for economic and financial stability risks and} opportunities from digital money. The IMF's Independent Evaluation Office called for further investment in financial and macrofinancial analysis (IEO 2019). The Comprehensive Surveillance Review (CSR, 2021a) recognizes that digital technology will have a major impact on future economic outcomes and shape the international monetary system. The CSR further underscores the need for a better understanding of how digital technology, together with other developments, impacts economic stability, and has identified ensuring economic sustainability a surveillance priority. Moreover, the Executive Board noted that, as digital money gains prominence, Fund surveillance should explore its potential benefits, as well as risks and spillovers. Similarly, the 2021 FSAP Review (IMF 2021b) emphasized the need to incorporate new risks from the evolving financial sector landscape, including public and private digital money.

\section{Reflecting these priorities in the Fund's regular dialogue with its members, through} Article IV consultations and FSAP missions, and in multilateral surveillance will be critical. ${ }^{1}$ Table 2 illustrates this congruence. Dark blue squares capture main areas of focus, and light blue occasional or secondary areas of focus. Taken together, surveillance should coverage most policy issues emerging from digital money. By contrast, the current coverage of digital money issues in surveillance is very limited. Some Article IVs have discussed arising challenges on an ad-hoc basis (such as the Bahamas on (BDC), and a few FSAP pilots (such as Singapore and Switzerland) have covered fintech issues going beyond digital money. Multilateral products are only starting to discuss implications of digital money developments. The limited coverage, as discussed later, stems in part from the novelty of the issues, and also from the lack of internal capacity.

Table 2. IMF Surveillance Would Cover the Main Areas of Policy Implications Stemming from Digital Money Adoption

\begin{tabular}{|c|c|c|c|c|c|c|}
\hline & \multicolumn{2}{|c|}{ Bilateral products } & \multicolumn{4}{|c|}{$\underline{\text { Multilateral products }}$} \\
\hline & $\begin{array}{c}\text { Article } \\
\text { IV }\end{array}$ & FSAP & GFSR & $\begin{array}{c}\text { WEO/ } \\
\text { REO }\end{array}$ & $\begin{array}{l}\text { Fiscal } \\
\text { Monitor }\end{array}$ & $\begin{array}{l}\text { ESR/ } \\
\text { Spillover }\end{array}$ \\
\hline International effects & & & & & & \\
\hline Broad domestic effects & & & & & & \\
\hline Narrow domestic effects & & & & & & \\
\hline
\end{tabular}

Source: Authors' illustration; dark blue squares capture main areas of focus, and light blue occasional or secondary areas of focus.

\footnotetext{
1 Since 2010, financial stability assessments have been a mandatory part of surveillance for members with systemically important financial sectors (SIFS). Currently the Fund considers 47 jurisdictions as having SIFS. FSAP assessments for other members are conducted on a voluntary basis, and the key findings and recommendations of an FSAP assessment inform surveillance.
} 


\section{Article IV Consultations}

\section{All core areas of Article IV consultations are potentially impacted by digital money} adoption, though country coverage will be selective. As discussed, the new policy issues include monetary, exchange rate, financial sector, fiscal, structural, and in relevant cases, spillovers. Article IV consultations would thus cover broad domestic effects of digital money adoption, as also recommended in the CSR (IMF 2021c), as well as narrow domestic effects, and international effects. Coverage will need to focus on countries and areas where implications of digital money adoption are macro-critical (or becoming macro-critical). Coverage would thus be decided on a case by case basis. A recent example is the initial coverage of CBDC in the Bahamas Article IV in the main text and a dedicated annex on the "Sand Dollar."

\section{Table 3 identifies the main deliverables related to Article IV consultations and provides an} estimate of coverage in the steady state. For the purposes of this paper, the steady state is expected to be reached in about 3 years. However, the steady state will continue being a period of rapid change, as argued earlier-continuous evolution and regular discrete jumps is a defining feature of the digital world. Table 3 splits deliverables into direct engagement, and surveillance-specific analytical foundations, following the framework of Figure 2. Estimating the coverage of Article IV engagements is difficult for two reasons. First, the timing and extent of digital money adoption (or exposure to spillovers) and related policy challenges will vary by country and over time. And second, the capacity of country authorities to engage on digital money will vary significantly. In 3 years and beyond, we expect issues related to digital money to be of sufficient importance to warrant some coverage in about a half to two thirds of Article IVs. Numbers are roughly based on internal surveys of mission chiefs related to IMF (2021). At the end of 2020, more than 80 percent of central banks were studying CBDCs. Some countries are or will soon be piloting CBDC (and eventually adopt it), others will see significant growth of stablecoins, eMoney, digital assets, in some cases cryptoassets, and new innovations that are still difficult to forecast. And even where adoption may be low or sluggish, spillover effects such as on capital flows, foreign exchange regimes, and currency substitution will arise. Thus, many countries will be evaluating, or continuing to adapt, relevant legal and regulatory frameworks, policy conduct, and institutional designs. However, while a wide array of countries will be affected, Article IV coverage will vary from full-fledged analysis to narrow review, such as of new laws. The resource estimates discussed later thus assume a relatively light coverage on average, amounting to about one third the involvement of a dedicated expert.

\section{Table 3. Products and Tools for Article IV Consultations and Expected Output}

\section{Deliverables}

Direct engagement

Article IV coverage of macro-critical digital money implications, with initial focus on jurisdictions with systemically important financial sectors, high, early, or rapid digital money adoption, or spillovers.

\section{Coverage}

$1 / 2$ to $2 / 3$ of countries per year (light coverage on average)

Surveillance-specific policy and tools 
Table 3. Products and Tools for Article IV Consultations and Expected Output (concluded)

Upgrade and maintain the Vulnerability Exercise (VE), the Systemic Risk Ongoing

Tracker (SRT), and over time, potentially integrate with the financial programing framework. Ensure digital money aspects are reflected in the Consistent Policy Assessment (CPA) tool. (synergies with other tools)

Develop and maintain country-specific tools.

Ongoing

Sources: Authors.

\section{FSAP}

17. The scope of FSAP missions would continue to be determined on the basis of risks arising in the three pillars (risk analysis, oversight, and safety nets). The approach offers sufficient flexibility to adjust to an evolving financial landscape and shifts in the interests of the authorities. The implications of digital money adoption would be covered as these become of systemic importance to financial stability. As such, the focus of the FSAP would fall on the narrow domestic effects mentioned earlier.

\section{Analysis of risks arising from digital money will be reflected in the main FSAP report and}

technical notes. Table 4 captures the FSAP deliverables related to digital money, including plans to continue digital money-related pilots as done in the recent FSAPs for Korea, Singapore, and Switzerland. Moreover, assessment tools will need to be upgraded to incorporate new sources of risks, as well as guidance and recommendations issued by international standard-setting bodies. Reference notes for FSAP mission chiefs on targeted topics will prove useful and will be needed on an ongoing basis (some are already being prepared with the World Bank). ${ }^{2}$ New standards and codes will eventually evolve from standard setters, with contributions from Fund staff, for formal assessments. Until then, policy views would follow interim discussion and guidance, as agreed with the Board. Finally, data availability will play a critical role in determining the feasibility and quality of in-depth risk analysis.

Table 4. Products and Tools for FSAP Missions and Expected Output

\section{Deliverables}

\section{Direct engagement}

Expand and deepen the analysis of risks related to digital money (as agreed with county authorities and depending on the systemic importance of digital money in the jurisdiction, as well as available guidance and standards).

\section{Coverage}

Most FSAP

missions, where

relevant

\footnotetext{
2 Initial recommendations and guidance is starting to emerge, such as by the Financial Stability Board on global stablecoins, the Basle Committee on Banking Supervision on the prudential treatment of cryptoassets, and by the Committee for Payments and Market Infrastructure on applying the Principles for Financial Market Infrastructure (PFMI) to stablecoins.
} 
Table 4. Products and Tools for FSAP Missions and Expected Output (concluded)

Surveillance-specific policy and tools

Reference notes for FSAP mission chiefs, drawing on guidance and standards and codes set by international standard-setting bodies.

Participate in international working groups to update and develop 2-3 groups standards relevant for the FSAP.

Develop, update, and maintain approaches and models to assess resilience to continuously evolving risks from digital money for banks, financial market infrastructures, and payment system (including "bespoke tools" developed during missions). (synergies with modelling work)

Develop, update, and maintain tools to evaluate materiality of risks Occasional related to digital money, to inform FSAP coverage.

Source: Authors.

\section{Multilateral Surveillance and Flagships}

\section{The approach to integrating digital money implications in multilateral surveillance} products is similar to that for the bilateral surveillance and FSAP products discussed above. The multilateral surveillance products include the bi-yearly flagships, namely the World Economic Outlook (WEO), the Global Financial Stability Report (GFSR), Fiscal Monitor, and the Regional Economic Outlooks (REOs). The annual and more targeted products include the External Stability Report (ESR) and the Annual Report on Exchange Arrangements and Exchange Restrictions (AREAER). The bi-yearly flagship reports would focus on the broad domestic effects of digital money adoption, while occasionally also highlighting international implications. The GFSR in particular would offer regular coverage of systemic risks stemming from digital money adoption. The yearly publications (and the WEO chapter on spillovers) would focus more squarely on international implications. This is especially important to not lose track of big-picture developments related to the IMS. Related deliverables are listed more fully in Table 5.

Table 5. Products and Tools for Multilateral Surveillance and Expected Output

Deliverables

\section{Direct engagement}

Regular coverage (as discussed above; chapters may not be entirely dedicated to digital money, but will include a discussion/ respond to developments).

\section{Coverage}

Across products, with periodic dedicated chapters

Surveillance-specific policy and tools 
Table 5. Products and Tools for Multilateral Surveillance and Expected Output (concluded)

Develop and maintain models, frameworks, indicators, and policy lines relevant to multilateral surveillance products. For instance, review and Ongoing update the external balance assessment (EBA) methodology, growth at risk models, forecasting models, and key risk indicators. (synergies with other modelling work)

Source: Authors.

\section{B. Capacity Development}

20. Capacity development in the digital money space will need to ramp up rapidly to avoid a digital divide, and ensure new solutions work for all countries. Projects would remain demanddriven, though guided by the macro-criticality of the request. The aim of projects would be to help countries evaluate benefits, risks and challenges of specific forms of digital money, estimate policy tradeoffs, and strengthen their readiness and skills to enact policy reforms, as well as evaluate, design, and monitor new infrastructures (including interoperable $C B D C$ ) and build and analyze datasets. The actual development of infrastructure would not be a central focus, and one that the Fund could leave to partner organizations, such as the World Bank or BIS Innovation Hub, as discussed later.

\section{Demand for capacity development related to digital money is rapidly increasing and}

expected to remain sustained. This is reflected in a recent internal survey discussed in IMF (2021) and area departments' medium-term capacity development strategies. Areas of particularly rapid growth are expected to be CBDC implications and design (the survey reveals more than 100 countries are actively exploring $(B D C)$, regulation of private money schemes, payment strategies, digital risk management (including cyber security), legal and regulatory frameworks, data collection, as well as on tax and transfer policies and their institutional implications (including on public organizations, governance structures, skills, and legal aspects). Today already, the Fund has seen a jump in requests for technical assistance and regional workshops on these topics. Due to resource constraints, however, some requests are having to be postponed or turned down. But even with more resources, priority would continue to depend on macro-criticality, as well as expected traction and impact.

\section{Capacity development would focus on lower income, and emerging market economies.}

The Fund could engage in both bilateral and regional capacity development, and potentially work with several countries at once on issues related to cross-border payments. Regional projects, including through regional capacity development centers ( $R C D C s)$, have proven to be effective at getting countries up to speed on basic issues related to digital money, before providing more targeted bilateral assistance. In addition, the Fund could act as a bridge between the development and international community, central banks, and ministries of finance to help transfer lessons and experience. Table 6 provides an overview of projects.

23. Capacity development would be provided by multiple departments at the Fund, and in collaboration with experts, including long-term experts in RCDCs. Given the delicate nature and 
novelty of projects related to digital money, capacity development projects would initially be provided mostly by IMF staff on a more limited basis, and with the collaboration of short-term experts to help transfer the more hands-on and technical knowledge. As experts are identified and funding secured, the balance would gradually shift to greater participation by long-term experts in RCDCs, backstopped by IMF staff, first in the more advanced regions, then in the lower-income regions where countries are looking to leapfrog. In steady state, the expectation is that about half the projects would be led out of RCDCs, a quarter by short-term experts, and another quarter by IMF staff. Table 6 identifies about 50 bilateral projects per year in steady state led by IMF staff or short-term experts as part of the IMF01 budget. These would be provided principally out of FAD, ITD, LEG, MCM, STA, and COM on occasion (to help with financial literacy, public consultations, as well as explaining policy decisions that can be initially perceived as controversial or complicated). ${ }^{3}$

\begin{tabular}{|l|l|}
\hline \multicolumn{2}{|c|}{ Table 6. Products and Tools for Capacity Development and Expected Output } \\
Deliverables & Coverage \\
\hline Direct engagement & 50 projects per year \\
\hline Bilateral CD engagements. & 5 per year \\
Targeted evaluations of cyber-security, regulatory, and legal framework & \\
readiness (for infrastructure/ schemes that are not yet systemic, or for \\
countries not receiving FSAPs).
\end{tabular}

\footnotetext{
${ }^{3}$ By way of comparison, one of these departments-MCM-delivers about 1000 projects per year, around 100 of which are led by headquarters based staff, while the remainder is about evenly split between short-term experts and long-term experts. About 30 percent of projects focus on central banking operations, and 40 percent on financial sector supervision and regulation. The estimated projects above are thus a small fraction of projects on any one topic in MCM alone. Capacity development projects across the Fund are about 5 times greater, nearing 5000 projects per year.
} 


\section{Analytical Foundations}

\section{General analytical foundations are essential to underpin effective surveillance and} capacity development. As defined earlier (and illustrated in Figure 2), these comprise two elements. Corresponding deliverables are captured in Table 7.

\section{First, the Fund must develop policy views as well as tools to be in a position to provide} independent, effective, innovative, and constructive advice. These will also allow the Fund to influence policy debates that affect the IMS, and proactively suggest a broad vision and corresponding set of measures to ensure the IMS remains stable and efficient. The tools relevant to these foundations entail basic models, methods, and frameworks to be adapted for country-specific surveillance and capacity development. They also include the development of a data hub essential to policymaking but currently lacking for public and internal use, and participation in international working groups (such as those set up to implement the G20 Roadmap to Enhance Cross-border Payments). These working groups develop policy principles and standards to guide countries' development, regulation, and assessment of digital money. The Fund's role is essential to bring a broad policy and macro-financial perspective (for instance, principles for cross-border interoperability must take into account spillovers and CFMs), and to represent the interests and needs of all countries, as working group members tend to be drawn from a small number of countries with a more narrow focus.

\section{The second element of the analytical foundations comprises support activities. Internal} training would be provided in the form of courses and workshops to help bring economists up to speed on policies and tools of common relevance to country groupings, and mainstream the analysis of digital money, based on a solid understanding of the strengths and limits of the underlying technologies. Support also includes information sharing and coordination of the workstreams related to digital money, as well as partnerships with other stakeholders (more below).

Table 7. Deliverables and Coverage for Analytical Foundations

Deliverables

Development of policy and tools

Engage with the IMF Board (meetings and informal seminars) to seek feedback and guidance given the evolving nature of policy questions and innovations.

Contribute to international policy debates through Staff Discussion Notes (SDNs), Fintech Notes, and How-To Notes, as well as management engagements and annual/spring meetings.

Actively participate in international working groups tasked with setting standards, regulatory guidance, and/or facilitating policy coordination (excluding the working groups noted above relevant for FSAP guidance).

Develop a publicly available data hub with datasets relevant to digital money adoption and related policy implications.

\section{Coverage}

1 engagement per year (+ informal seminars as requested)

4 publications and 1 major event per year 5 per year

Ongoing 
Table 7. Deliverables and Coverage for Analytical Foundations (concluded)

Consider issuing "calls for proposals" (hackathons-following experience in 1 per year $F A D$ in revenue administration and public financial management) inviting private sector firms to propose solutions to a policy question (such as monitoring capital flows), for the benefit of country authorities, for which engaging with the private sector is more complex given their role as potential regulators and clients.

Support activities

Internal training. Create, maintain, and provide courses and workshops to bring IMF staff up to speed and stimulate discussions on policy issues $\&$ share lessons/ experiences.

Information sharing. Create and maintain resource/ knowledge hub unifying all relevant IMF output...

... and engage in brainstorming across departments and functions, to 3-4 per year ensure continuous learning and sharing of experiences, tools, and policies. Coordination, across digital money projects, with other related workstreams (e.g. climate, inclusion, fragile states), and external stakeholders.

Ongoing

At least 4 sessions per year Ongoing

Source: Authors.

\section{PARTNERING}

27. The Fund cannot only rely on internal resources alone to help members tackle the policy challenges raised by digital money adoption. It must closely partner with other stakeholders while minimizing overlap and duplication of work. This section discusses "guidelines of engagement" which the Fund will adopt to underpin successful partnerships. The section then highlights the Fund's core competencies and discusses how other stakeholders can complement its work.

\section{A. Guidelines for Engagement and Core Competencies}

\section{To build successful partnerships, the Fund will:}

- Remain within its mandate;

- Build on core competencies;

- Minimize overlaps;

- Seek to collaborate through standing arrangements, if not on a project-by-project basis;

- Be transparent about workplans and priorities;

- Recognize, cross-reference, and disseminate the work of other stakeholders;

- Engage in debates with, and seek feedback from, other stakeholders;

- Nevertheless, develop independent policy views and take responsibility for its policy advice. 
29. Four core competencies stand out for the Fund. As discussed in IMF (2021), these are:

- Near universal membership across countries and institutions, offering an ideal platform to bring together ministries of finance and central banks to discuss spillover effects and issues close to national economic policy interests, to propose policy solutions targeted to the needs and capacity of all countries, to offer and develop a common vision for the IMS, and to foster a common understanding of corresponding design principles for digital money.

- Core policy focus on macroeconomic, macrofinancial, exchange rate, fiscal, and spillover issues and their interconnections at the center of the IMS.

- Broad expertise, bringing together economists, financial sector experts, technical and technology experts, and lawyers on common projects, reflecting the interconnected implications of digital money.

- Unique ties to member countries through surveillance and capacity development, which the Fund can leverage to spur open and constructive discussions on a bilateral, regional and global level, to offer its independent analysis to enrich the policy debate and ensure its resilience in an environment of rapidly evolving views, and to facilitate peer-to-peer learning and the sharing of policy lessons.

\section{B. Complementarities with Other Stakeholders}

30. Based on these core competencies, the Fund will seek to collaborate with other key stakeholders. Five different groups of stakeholders exist, each of which complements well the work of the Fund, and whose work the Fund can enrich. The Fund would aim to establish memoranda of understanding to clearly delineate the work with some organizations, engage in joint projects as opportunities arise, enlist a liaison officer as needed to coordinate projects, and earmark some positions to host representatives from other organizations for limited periods to encourage knowledge sharing, transparency, and strengthen personal ties between organizations.

31. The first major stakeholder is the World Bank, given its proximity to the Fund. The World Bank is a natural partner for the delivery of the Fund's core activities, including surveillance (joint FSAP), capacity development (cross-staffing and cross-referencing of TA and training missions), and analytical foundations (joint development of tools and papers, exploration of technology, and mutual comments-as for instance the Bali Fintech Agenda, 2018). Collaboration is ongoing on all fronts, as with the joint development of FSAP reference notes on risks stemming from digital money. The World Bank complements well the Fund's work with its focus on development, financial inclusion, govtech, remittances, data collection, evaluation of technologies, and implementation of infrastructure, as well as its ability to engage in procurement to develop concrete solutions in countries with insufficient means or capacity.

32. The second group consists of other institutions active in the area of digital money, such as the Bank for International Settlements (BIS) and the BIS Innovation Hub (BISIH). The former has a small though active and forward-looking research team, and the latter is actively engaged in 
"fostering collaboration on innovative financial technology" and exploring concrete solutions involving different forms of digital money. The Fund can help channel the needs of non-member central banks and ministries of finance to the $\mathrm{BISIH}$, and inversely to disseminate findings and knowledge from the BIS and BISIH to non-member country authorities. With its focus on the IMS, the Fund would ideally also be able to suggest key projects to the $\mathrm{BISIH}$, such as to leverage digital money to improve the effectiveness of CFMs. The BIS and BISIH can also complement the work of the Fund by contributing experts to Fund capacity development projects. The BIS and BISIH are already close partners: links are tight at all levels, work agendas are discussed and the Fund has held various consultation meetings about this very strategy.

\section{The third group comprises entities that are especially effective at creating consensus} around policy views and standards of immediate priority. These are the G7 and G20, as well as the standard setting bodies such as the Financial Stability Board (FSB), the Committee on Payments and Market Infrastructure (CPMI), and the Financial Action Task Force (FATF). The Fund can complement the work of these important stakeholders by bringing its macro-financial expertise and policy focus to bear in international working groups (such as the ongoing work on the G20 Roadmap to enhance crossborder payments), and by representing the needs and objectives of countries that are not part of these more selective groups. The Fund can also disseminate policy views and standards through outreach events as currently planned on targets for cross-border payment reforms and through outright surveillance activity, and engage in assessments of standards developed by standard setters, through its capacity development activity as mandated. Conversely, these groups help the Fund institutionalize its policy views, to the extent these are shared among the groups' members.

\section{The fourth group comprises country authorities-including central banks, ministries of} finance, but also regulatory, supervisory, anti-trust, and other agencies and ministries. As the Fund's main shareholders, clearly country authorities set the priorities for the Fund's work. But they can also complement the Fund's activities by contributing experts to capacity development as is ongoing, and thereby help share experiences, lessons, and best practices with their peers. Moreover, as many countries are actively involved in developing policies related to digital money, and exploring topics common to the Fund's workplan, the Fund can help countries learn from each other's experiences given its global membership. Moreover, some direct collaboration is also possible and very welcome, although the Fund must ensure uniformity of treatment and the independence of its views.

35. The fifth and last group includes other stakeholders. These include private sector entrepreneurs, academics, privacy advocacy groups, representatives of civil society, think tanks, and others. While some of these groups may have narrow, partisan agendas, they are nevertheless important partners for the Fund to stay abreast of latest developments and their broader impact on societies, and, conversely, for the Fund to provide an objective and far-sighted perspective.

\section{BUILDING INTERNAL CAPACITY}

36. This section reviews the building blocks necessary to build internal capacity as needed to deliver on the strategy. Four building blocks are identified: the skills mix; internal organization and processes; hiring guidelines; and resource needs. 


\section{A. Necessary Skills}

37. Five sets of skills are essential to support work on the implications of digital money. These are discussed in the April 2021 informal Board paper, and include: macro and fiscal economists; financial sector experts; technology and digital risk experts; lawyers; and data specialists. These skills would naturally draw on all relevant functional departments, as well as area departments. Table 8 gives a sense of the relevance of skills to each core activity and set of policy questions. While skills are relevant throughout, blue squares capture areas where skills would be used particularly intensively.

Table 8. A Wide Set of Skills Is Needed to Cover All Activities and Policy Questions

Bilateral surveillance Multilateral surveillance Capacity development Analytical foundations International effects Broad domestic effects Narrow domestic effects

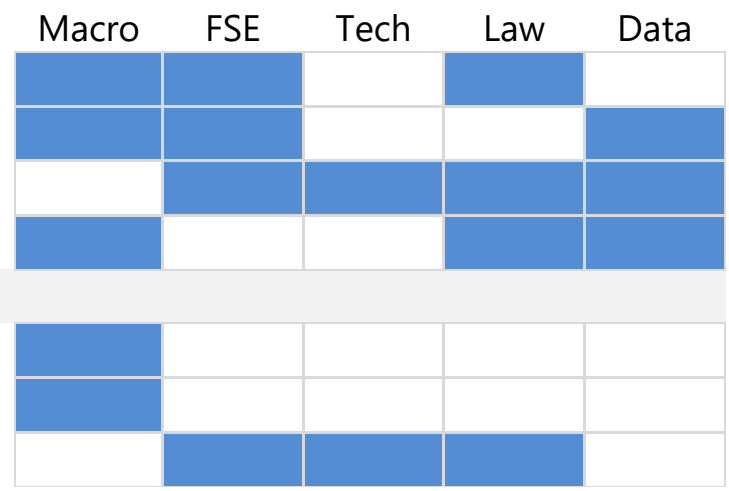

Source: Authors' illustration. While skills are relevant throughout, blue squares capture areas where skills would be used particularly intensively.

\section{B. Internal Organization and Process}

38. Internal structures and processes will support this ambitious effort. These will help coordinate work across departments, encourage internal debates about policy views, and foster a seamless transfer of information and ideas within and from outside the institution.

- Create an internal coordination group made up of 1-2 representatives of each functional and area department, with MCM acting as the secretariat. The group would be tasked with sharing departmental work plans, facilitating prioritization and collaboration, identifying areas where work would be desirable, and reporting to management and the Board on progress.

- Create an internal technology learning environment, in coordination with the World Bank, to maintain adequate staff awareness on the technologies powering digital moneys, their risks, trends and limitations.

- Leverage the Fund's new digital systems to channel and archive exchanges (about news, ideas, publications, meetings with entrepreneurs and policymakers, and divisional workplans). 
- Maintain an active seminar series for external speakers, and for staff to receive feedback on projects and help mainstream policy lines and tools. As discussed earlier, internal training will also be developed.

- Re-start, re-structure, and re-position the fintech external advisory group established in 2017, and integrate members more closely in analytical support and, to some extent, capacity development.

- Work with the Office of Innovation and Change (OIC) on details of operationalization and to draw on private sector initiatives and insights, COM to maintain awareness of this new work agenda and of ongoing output, KMU to develop an internal knowledge hub, and ITD to create internal training and workshops on relevant technologies and cyber risks..

39. An important objective of this strategy is to ensure that adequate resources are available for effective surveillance. As such, a balance must be struck between centralizing resources in functional departments and decentralizing resources in area departments. Centralization supports efficiency gains (optimal allocation, critical mass, maintenance of skills, fixed development costs), as well as consistency of views and evenhandedness. However, decentralization is essential to adapt analytical foundations to country circumstances, transfer ownership of policy messages, react quickly to incoming questions and requests from the authorities, and in return learn from country responses to update the analytical foundations. Innovative approaches will be needed in addition to staffing Article IV missions with appropriate functional department experts (in addition to experts focused on general macrofinancial issues), and upgrading skills of area department staff so that the more established issues relating to digital money can be covered directly, while staff of functional departments extend the analytical foundations to newly emerging topics, given the continuous transformation that is expected.

\section{Resource Implications}

\section{Increased resources will be required to meet the objectives outlined in this strategy. A} total of 55 FTE additional staff and experts are needed to implement the Fund's digital money strategy in steady state (assumed to be reached in about 3 years, and to represent a state where technology, digital money service, and policy challenges continue to evolve rapidly). This adds to current resources of 15 FTEs, while IMF02 resources would be used to further expand capacity development

opportunistically. For this exercise, no distinction is made between contractuals, short-term experts, and Fund staff in estimating FTE requirements, as long as all would be covered by IMF01 budget, so as not to bias eventual dollar estimates.

\begin{tabular}{|ccc|}
\hline Table 9. Estimated Resource Split Needs by Core Activity & $\begin{array}{c}\text { Percent } \\
\text { Perce } \\
\text { of total }\end{array}$ \\
\cline { 2 - 3 } Direct country work & $\mathbf{4 4}$ & $\mathbf{6 3}$ \\
Bilateral surveillance & 23 & 33 \\
AIV & 15 & 22 \\
FSAP & 8 & 11 \\
\hline
\end{tabular}




\begin{tabular}{|c|c|c|}
\hline \multicolumn{3}{|c|}{$\begin{array}{l}\text { Table 9. Estimated Resource Split Needs by } \\
\text { Core Activity (concluded) }\end{array}$} \\
\hline Capacity development & 21 & 30 \\
\hline Multilateral surveillance & 4 & 5 \\
\hline Policy and tools & 17 & 25 \\
\hline Adapt to surveillance/ CD & 8 & 12 \\
\hline Develop & 9 & 13 \\
\hline Support activities & 5 & 7 \\
\hline
\end{tabular}

41. This headline estimate can be broken down as shown in Table 9. Resource needs are heavily tilted towards direct country engagement (63 percent), with about an even split between bilateral surveillance and capacity development. Multilateral surveillance is expected to account for 5 percent of resources, while developing policy views and tools for all functions would require 25 percent of resources (about evenly split between developing models, frameworks, data, and view, and adapting these to specific countries, projects, and evolving technologies).

\section{These resource estimates reflect the far-reaching and interconnected implications of} digital money across the policy spectrum. They follow from applying standard cost estimates to each deliverable identified in the earlier tables. Specifically:

\section{- Country work:}

- Thus far, involvement in Article IV surveillance has responded to ad-hoc requests to help on technical reviews (e.g., Sweden and the Bahamas 2021 AIV), and was limited to 2-3 per year. The Fund also occasionally assesses fintech-related risks in FSAP pilots (again 2-3 per year). The planned ramp up would support participation in, and review of, about a half to twothirds of Article IVs every year, though with less intensity on average than dedicated to other macro-financial issues (about 0.1 FTE per mission as opposed to $0.3 \mathrm{FTE}$ ), and targeted coverage of digital money in about 12 FSAPs annually (approximately 0.6 FTEs per FSAP considering coverage of each of the 3 pillars).

- The Fund has begun to engage in capacity development in the areas of CBDC, cyber security, legal frameworks, financial integrity, payment strategies, and leveraging digital money for fiscal transfers, but this too is at early stages (about 10 missions per year). The increase in resources would support the planned ramp up to about 60 activities per year by IMF staff and short-term experts out of FAD, ITD, LEG, MCM, STA, and COM on occasion, at about 0.3 FTEs per mission (assuming 2.5 people per project). As discussed earlier, in steady state about the same number of the projects would be led out of RCDCs by long-term experts (or short-term experts backstopped by long-term experts) covered by the IMF02 budget. 
- Multilateral surveillance, policy and tools, and support activities

- On the international front, the Fund has been able to contribute to important G7 and G20 efforts such as to establish recommendations for stablecoin regulation, and to enhance cross border payments, by staffing working groups (about 5 per year). Further resourcing will be needed, however, to more proactively representing the wide membership on working groups (such as by organizing workshops to source input). Additional resources would allow the Fund to staff about 7-8 international working groups per year (0.3 FTE each).

- Currently, digital money has mostly been absent from multilateral surveillance and while staff have contributed to developing policy views through impactful papers (about 1-2 per year), it runs the risks of becoming reactive and falling behind the curve as the speed of change accelerates. In addition, policy work has been limited by sporadic and insufficient data coverage. The resource increase would support sustained, proactive leadership in core areas to develop, tailor, and maintain policy views and tools for country work (in part through full-blown cross-departmental policy papers requiring about 1.5 FTEs each, and in part through guidance notes, as well as more regular and targeted updating of tools requiring 0.5 FTE each). The Fund would also be able to provide a publicly available data hub (about 3 FTEs), and engage in internal training, information sharing, and internal and external coordination (about 1 FTE each), all of which are essential to mainstream the work on digital money.

43. These estimates take into account mitigating factors. One-off investments to reach steady state were excluded from the estimates. Special care was taken not to double count (for instance, models developed for AIV surveillance but also relevant for FSAP missions). Moreover, synergies were sought with existing macro-financial expertise, such as to design models for bank stress-testing in response to disintermediation risks. Synergies were also noted with existing expertise in conventional financial market infrastructure, such as to evaluate the stability and efficiency of payment systems. In addition, synergies and complementarities with other new workstreams were also taken into account. For instance, foundational work in fragile states to build institutions is needed before advices on digital money can be provided. Likewise, capacity among the climate team will help assess the carbon footprint of digital money initiatives and propose policies to contain these.

44. As noted, the work on digital money and efforts to enhance capacity would be phased. A steady ramp-up in overall resources will be phased differently for the various components of the work. The initial investment will focus on building the analytical foundations to engage with countries on digital money. Again, these cover the policy lines and tools, as well as training and review capacity. While surveillance and capacity development will also begin immediately, rapid growth will occur somewhat later, in part to leverage stronger analytical foundations, and in part as countries themselves build absorptive capacity. As argued earlier, however, it is important to engage with countries before issues become macro-critical and policy challenges fully materialize, to conserve degrees of freedom to affect the digital money landscape. The strategy sees capacity development increasingly being delivered by long-term experts (hosted in RCDCs, funded by IMF02). A stylized sketch of the phasing 
patterns (not levels) of the digital money strategy's main building blocks is presented in Figure 4. Taken together, the panels show an aggregate ramping up of resources to steady state.

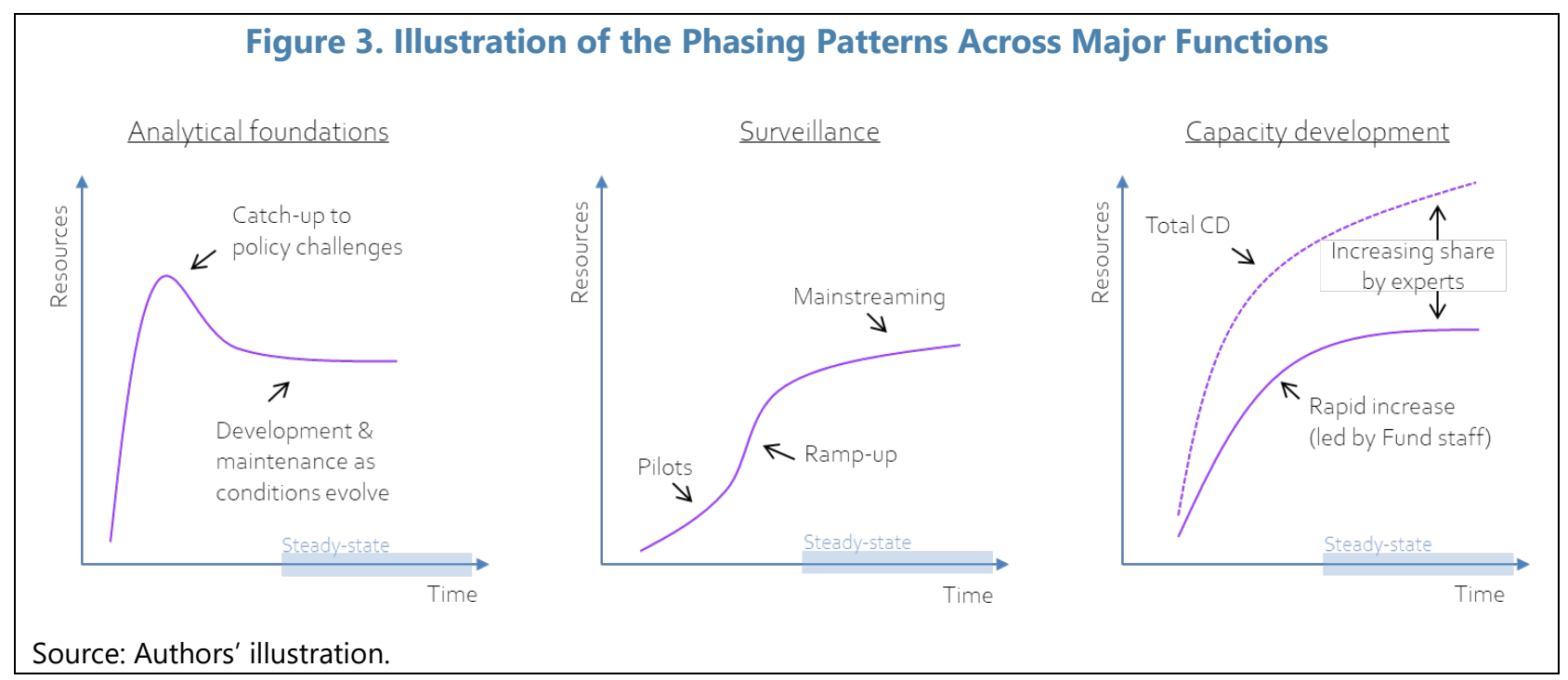

45. A recruitment and absorption strategy would be developed. Hiring a significant number of new staff comes with risks that will need to be managed. The main risk stems from the capacity to find, recruit, attract, and absorb new high-caliber and diverse talent into the organization. Growth would thus occur over the next three years, with an approximately linear progression in hiring (although structural lags in identifying talent and moving people to headquarters would likely lead to more hiring the second and third years relative to the first). Moreover, opportunities to enlarge and galvanize the pool of potential hires would be sought, such as rotations of staff coming from other organizations or central banks. A mix of contractual and staff appointments would provide flexibility to adapt resources as technology and policy challenges evolve.

46. Lesson may be useful from other areas, such as ramping up macroprudential policy advice and mainstreaming macrofinancial surveillance. In both cases, resource constraints left gaps in fully adapting the Fund's core activities of surveillance and capacity development (Box 2). This risk applies equally to the important work on digital money, a topic that is wide-ranging, evolving fast, subject to strong network effects, has strong implications for the IMS, and forces policymakers to rethink basic economic arrangements (such as what is money, and how might capital accounts be managed).

\section{Box 2 offers more granular lessons that will also apply to work on digital money. These}

lessons are imbedded in plans to rollout implementation of the digital money strategy, addressing:

- The need for effective knowledge sharing mechanisms and buildup of expertise across all departments and functions;

- The need to acquire talent through hiring to accelerate the buildup of expertise and to adequately attend rapidly evolving needs; 
- The speed at which the knowledge frontier can evolve and the need to invest early to close the knowledge gap;

- The self-reinforcing cycle in learning from targeted country engagements and wider development of analytical foundations;

- The importance of continuous learning, also through more unstructured "brainstorming," across departments and involving participants in all functions.

\section{Box 2. Lessons from Ramping-up Macroprudential Policy Advice and Mainstreaming Macrofinancial Surveillance}

\section{Macroprudential policy}

The transformation of the U.S. subprime crisis into the 2008 "global financial crisis" came as a major intellectual shock to the IMF and its member countries. A macroprudential perspective was needed to identify and mitigate systemic financial risk.

The IMF responded quickly and engaged in this workstream to the best of its abilities, developing a framework of analysis, policy processes, surveillance guidance for Article IV and FSAP missions, a discussion of interactions with CFMs, and novel datasets (IMF 2011, 2013, 2014, 2017, 2018). Its close collaboration with the FSB and BIS culminated in an influential stocktaking of macroprudential frameworks and experiences in 2016 ("Elements of Effective Macroprudential Policies," IMF/FSB/BIS 2016).

However, despite the IMF having become a global thought leader in the field, a decade later the Comprehensive Surveillance Review (CSR) suggested that "lack of expertise" and "competing priorities" constrained the Fund's progress in deepening and integrating systemic risk analysis and macroprudential policy advice in Article IV consultations, thus policy impact (IMF 2021c). Indeed, while Fund staff assembled a core team of macroprudential policy experts with deep knowledge and rich experience, the expertise across departments remained limited.

Looking ahead, the CSR thus calls for "deeper knowledge on the effects of macroprudential policy and its interaction with other policies," to be achieved through "learning from country experiences and additional analytical work on the intended and side effects of macroprudential policy tools, including distributional implications and interactions with other policies."

\section{Macrofinancial surveillance}

The initiative to mainstream macrofinancial surveillance in Article IV consultations was an important part of the Fund's efforts to step up financial surveillance in the wake of the global financial crisis. The initiative started with 24 pilot countries in 2015, expanding to 67 countries in 2016 and 128 in 2017, and the full membership three years later, in 2018 (IMF 2017, 2021). Subsequent reviews, reporting progress made since the launch of the initiative, provide takeaways that may be useful for implementing the digital money strategy.

First, the 2018 Interim Surveillance Review (IMF, 2018) concluded that the piloting approach, including through the mainstreaming initiative, generated key lessons:

- Learning is effective when pilots are rolled out in waves as operational experience gained from the initial wave helps refine frameworks and practices for subsequent waves.

- Selectivity in prioritizing coverage of issues and streamlined review was in some cases helpful in supporting more in-depth analysis and granular, tailored policy advice. 


\section{Box 2. Lessons from Ramping-up Macroprudential Policy Advice and Mainstreaming Macrofinancial Surveillance (concluded)}

- Brainstorming sessions enhanced dialogue outside the formal review process as they helped ensure sufficient attention to prioritization, relevant peer country experience, and integrating specific analytical approaches into staff's broader analysis.

- Learning took place across initiatives. Lessons from macrofinancial training, for instance, helped inform inter-departmental training clinics on macrostructural issues.

- Leveraging outside expertise, including through externally financed consultants, was helpful.

Second, a follow-up examination during the 2021 Comprehensive Surveillance Review (IMF 2021c) found that participation in pilots to mainstream macrofinancial surveillance was associated with higher quality of systemic risk analysis and macroprudential policy advice in subsequent years. At the same time, the review concluded that, despite previous efforts, gaps in macrofinancial analysis persisted, especially for emerging market and developing economies. Echoing an earlier evaluation by the Independent Evaluation Office (IEO, 2019), the review attributed these gaps to insufficient resources and limitations in macrofinancial expertise.

\section{CONCLUSION}

48. The rise of digital money has profound, wide-ranging, and interconnected implications for domestic economic and financial stability and the stability of the IMS. As the Fund has a mandate to help support these important objectives, it must step up to better serve its membership. The Fund has a mandate to monitor, advise on, and in some cases guide this transition. The Fund is well positioned to do so given its unique core competencies, and well-established activities including surveillance, capacity development, and lending, as well as corresponding analytical foundations. However, the Fund needs to rapidly increase resources and deepen its skills to be effective. Just as importantly, the Fund must strengthen partnerships with complementary organizations, while remaining committed to its mandate and to minimizing overlaps. 


\section{ISSUES FOR DISCUSSION}

- Do Directors agree that the Fund's role would need to evolve given the fast-changing developments with digitization?

- Do Directors agree with the proposed operational strategy to enhance the Fund's role on issues relating to digital money?

- Do Directors see any further areas that could be considered to better serve the membership?

- Do Directors agree with the request for additional resources that would be necessary to ensure Fund's effectiveness in this area? 


\section{References}

Adrian, Tobias and Mancini-Griffoli, Tommaso (2018). "The Rise of Digital Money" IMF Fintech Notes No. 2019/001.

Agur, Ari, and Dell'Ariccia (2019). "Designing Central Bank Digital Currencies," IMF Working Paper 19/252 (forthcoming on Journal of Monetary Economics).

Al-Sadiq (2021). "The Role of E-Government in Promoting Foreign Direct Investment Inflows," IMF Working Paper 2021/008.

Bank of England (2020). "Central Bank Digital Currency-Opportunities, Challenges and Design," Discussion Paper, March.

Bordo, Michael and Andrew Levin (2017). "Central Bank Digital Currency and the Future of Monetary Policy," NBER Working Paper 23711.

Brunnermeier, Markus K., James, Harold, and Landau, Jean-Pierre (2019). "The Digitalization of Money," NBER Working Paper 26300.

Čihák, Martin, and Sahay, Ratna (2020). "Finance and Inequality," IMF Staff Discussion Note 20/01. International Monetary Fund: Washington, DC.

European Central Bank (2020). Report on a Digital Euro. October 2020.

Gopinath and Stein (2019). "Banking, Trade, and the Making of a Dominant Currency," Quarterly Journal of Economics.

GSMA (2020). The State of Mobile Internet Connectivity Report 2020, GSMA.

lancu, Alina, et al. (2020a). "Reserve Currencies in an Evolving International Monetary System," IMF Departmental Paper No. 2020/002. November 17, 2020.

Independent Evaluation Office (IEO) of the International Monetary Fund (2019). "IMF Financial Surveillance Evaluation Report," January 29.

IMF, 2011, "Macroprudential Policy: An Organizing Framework." International Monetary Fund, March 14 (2011). https://www.imf.org/external/np/pp/eng/2011/031411.pdf

IMF (2012). "Modernizing the Legal Framework for Surveillance-An Integrated Surveillance Decision," IMF, July 17.

IMF, 2013, "Key Aspects of Macroprudential Policy." International Monetary Fund, June 10 (2013). https://www.imf.org/external/np/pp/eng/2013/061013b.pdf

IMF, 2014, "Staff Guidance Notes on Macroprudential Policy—Main Note and Detailed Guidance." IMF, (2014). https://www.imf.org/en/Publications/Policy-Papers/Issues/2016/12/31/Staff-Guidance-Noteon-Macroprudential-Policy-Detailed-Guidance-on-Instruments-PP4928

IMF, FSB, and BIS (2016), "Elements of Effective Macroprudential Policies—Lessons from International Experience." (2016) https://www.imf.org/external/np/g20/pdf/2016/083116.pdf 
IMF, 2017, Increasing Resilience to Large and Volatile Capital Flows-The Role of Macroprudential Policies, IMF Policy Paper (2017) https://www.imf.org/en/Publications/Policy-

Papers/Issues/2017/07/05/pp060217-increasing-resilience-to-large-and-volatile-capital-flows

IMF (2017). "Approaches to Macrofinancial Surveillance in Article IV Reports," IMF Policy Paper, May (Washington: International Monetary Fund).

IMF (2018). "Interim Surveillance Review," IMF Policy Paper, June (Washington: International Monetary Fund).

IMF, 2018, The IMF's Annual Macroprudential Policy Survey- Objectives, Design, and Country

Responses, IMF Policy Paper (2018) https://www.imf.org/en/Publications/Policy-

Papers/Issues/2018/04/30/pp043018-imf-annual-macroprudential-policy-survey

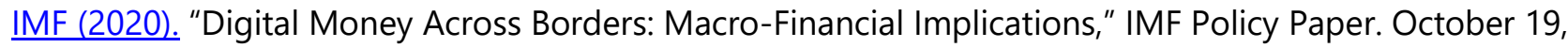
2020.

IMF (2021a). "The Rise of Digital Money-A Strategic Plan to Continue Delivering on the Fund's Mandate" IMF Policy Paper, April (Washington: International Monetary Fund)

IMF (2021b). "Financial Sector Assessment Program Review_Towards a More Stable and Sustainable Financial System" https://www.imf.org/en/Publications/Policy-Papers/Issues/2021/05/28/2021Financial-Sector-Assessment-Program-Review-Towards-A-More-Stable-And-Sustainable-460517

IMF (2021c). "Systemic Risk and Macroprudential Policy Advice in Article IV Consultations," Background paper for the 2021 Comprehensive Surveillance Review.

Mancini Griffoli, Tommaso, Maria Soledad Martinez Peria, Itai Agur, Anil Ari, John Kiff, Adina Popescu, Celine Rochon (2018). "Casting light on central bank digital currency," Staff Discussion Note, International Monetary Fund, November.

Obstfeld, Maurice (2004). "External adjustment," Review of World Economics (Weltwirtschaftliches Archiv), Springer; Institut für Weltwirtschaft (Kiel Institute for the World Economy), 140(4): 541-568 (December).

lbid (2012). "Does the Current Account Still Matter?" NBER Working Paper 17877.

Ouedraogo, Rasmané and Sy, Amadou N. (2020). "Can Digitalization Help Deter Corruption in Africa?" IMF Working Paper No. 2020/068.

Pazarbasioglu, Ceyla; Garcia Mora, Alfonso; Uttamchandani, Mahesh; Natarajan, Harish; Feyen, Erik, and Saal, Mathew (2020). "Digital Financial Services," World Bank Group, Washington DC (April 2020).

Research and Markets Report (June 2020) "Global Online Payment Methods 2020 and COVID-19's Impact."

Sahay, Ratna; Čihák, Martin; N'Diaye, Papa M.; Barajas, Adolfo; Mitra, Srobona; Kyobe, Annette J. ; Mooi, Yen N.; and Yousefi, Reza (2015). "Financial Inclusion: Can it Meet Multiple Macroeconomic Goals?" IMF Staff Discussion Note 15/17. International Monetary Fund, Washington, DC.

Schär, Fabian (2021). "Decentralized Finance: On Blockchain- and Smart Contract-Based Financial Markets," Federal Reserve Bank of St. Louis (February 5, 2021). 